\title{
REGLAMENTO PARA ACCEDER AL CERTIFICADO DE ESPECIALISTA EN ANATOMÍA CLÍNICA
}

\author{
Comité de Posgrado \\ Asociación Argentina de Anatomía Clínica
}

1) REQUISITOS PARA ACCEDER AL CERTIFICADO DE ESPECIALISTA (sin perjuicio de que aquellos con más de 15 años en la docencia opten por el régimen especial):

I) Ser egresado universitario de una carrera de Ciencias de la Salud o de Veterinarias, con al menos 5 años de graduado.

II) Desempeñarse o haberse desempeñado en la docencia universitaria, en el país o en el exterior, en cargo rentado o ad-honorem, por al menos 5 años.

III) Ser miembro de la Asociación Argentina de Anatomía Clínica (titular o adherente), con 5 años o más de antigüedad, al momento de optar por la certificación. Los Miembros Honorarios de la AAAC podrán postular al certificado siempre que sean también Socios Activos.

IV) Demostrar interés y participación en actividades de Anatomía Clínica (a criterio del Tribunal)

V) Ser autor o co-autor de 10 (diez) o más artículos completos publicados dentro de la especialidad, en revistas con referato externo e indizadas en bases de datos internacionales.

VI) Aprobar la evaluación teóricopráctica y de inglés que se receptará anualmente.

VII) Modalidad: En los meses de Mayo y Junio se realizará la inscripción de los postulantes, En Julio y Agosto se evaluarán los antecedentes. En Setiembre (fecha previa al Congreso o Jornada) se receptará la evaluación teórico-práctica. La evaluación incluirá 3 niveles de complejidad: a) Información, b) Comprensión y c) problemas o casos clínicos. Esta última instancia será en inglés. La evaluación se calificará como APROBADA o DESAPROBADA.

VIII) La decisión del Tribunal será inapelable. La certificación correspondiente se entregará durante el evento científico que tenga ese año la Asociación Argentina de Anatomía Clínica.

\section{2) DE LA CERTIFICACIÓN}

IX) Certificado:

a) Especialista en Anatomía Clínica con orientación a Anatomía Macroscópica Clínica, Quirúrgica e Imagenológica.

b) Especialista en Anatomía Clínica con orientación a Anatomía Microscópica, Embriología y Biología Molecular.

Tribunal: El tribunal estará com-puesto por 3 Socios activos de la AAAC, con certificación vigente y designados por el Comité de Posgrado. En caso de no poder 
cumplimentarse estas condiciones, se recurrirá a las medidas transitorias, designando un profesor extranjero.

XI) Certificación: La AAAC otorgará un certificado de Especialista con validez por cinco años, debiendo renovarse antes de finalizar este período. El vencimiento y falta de renovación por un período superior a dos años requerirá una nueva certificación. La nueva certificación no podrá realizarse apelando al régimen especial para profesionales con más de 15 años de trayectoria en docencia. La certificación vencida no tendrá validez para acreditar la especialidad.

XII) Requisitos para la Renovación de la certificación:

Deberá acreditar haber sido socio activo de la AAAC durante todo el período de la certificación.

Haber cumplimentado actividades que demuestren su interés en la Anatomía Clínica

Haber publicado (como autor o co-autor), al menos, 2 (dos) trabajos de Anatomía Clínica en revista con referato externo e indizada en bases de datos internacionales, en el período de los cinco años correspondiente a la vigencia del certificado anterior.

3) REQUISITOS DEL RÉGIMEN ESPECIAL PARA AQUELLOS CON MÁS DE 15 AÑOS EN LA DOCENCIA ANATÓMICA UNIVERSITARIA Y QUE QUIERAN ACOGERSE A ÉL:

A) Ser egresado universitario de una carrera de Ciencias de la Salud.

B) Ser miembro de la Asociación Argentina de Anatomía Clínica con 5 años de antigüedad. Los miembros Honorarios de la AAAC podrán postular para la certificación siempre que también sean socios ACTIVOS.
C) Ser 0 haber sido docente universitario, de universidad pública o privada, en el país o en el exterior, en cargo rentado o ad-honorem, durante más de 15 años (incluyendo el período de pregrado).

D) Demostrar interés y participación en actividades de Anatomía Clínica.

E) Ser autor o co-autor de 10 (diez) artículos completos de Anatomía Clínica (no resúmenes) publicados en revistas con referato externo e indizadas en bases de datos internacionales

\section{4) SE CONSIDERARÁ COMO INTERÉS O PARTICIPACIÓN EN ACTIVIDADES DE ANATOMÍA CLÍNICA:}

a) El dictado de diferentes temas en clases y cursos de pre y posgrado, referidos a la especialidad.

b) La asistencia y participación activa en Congresos y eventos científicos de la especialidad.

c) La sola asistencia a eventos científicos no acredita para optar a la certificación.

\section{5) MEDIDAS TRANSITORIAS:}

a) En la primera convocatoria el tribunal estará compuesto por profesores extranjeros designados ad-hoc. Si de la primera convocatoria no surgieran 3 miembros activos de la AAAC certificados, el Tribunal se completará con profesores extranjeros designados a este fin.

b) Desde la primera y hasta la convocatoria 2022 (inclusive) se aceptará que los artículos publicados puedan ser de Anatomía, Histología o Embriología en general, siempre que al menos 5 (cinco) tengan orientación clínica. 